\title{
MILITARIZAÇÃO DA EDUCAÇÃO: HIERARQUIA E DISCIPLINA
}

\author{
MILITARY EDUCATION: HIERARCHY AND DISCIPLINE
}

\begin{abstract}
Alessandro Pires Maciel Guirra ${ }^{1}$
RESUMO: O presente trabalho se pauta na análise e exposição de argumentos contrários e favoráveis ao modelo escolar de educação militar e cívico-militar nas escolas públicas brasileiras, demonstrando as interpretações legais existentes nas divergências para desenvolvimento e implementação desse modelo de ensino, evidenciando os artigos da Lei de Diretrizes e Bases da Educação Nacional com as disposições na Constituição Federal da República Federativa do Brasil, bem como seus princípios. Visando desmistificar o conteúdo, demonstra-se as bases da hierarquia e disciplina, bem como as dificuldades enfrentadas no ambiente escolar, as fundamentações para a existência ou não do modelo escolar militarizado, e pôr fim, a conclusão de que estamos longe de alcançar um modelo ideal de educação, devendo existir uma pluralidade de modelos a serem ofertados conforme anseios sociais. Para tanto, utilizou-se uma metodologia de caráter Exploratório para jogar luz sobre os pontos conflitantes dos debates acadêmicos e políticos face ao tema.
\end{abstract}

Palavras- chave: Hierarquia e Disciplina. Educação. Colégio Militar.

ABSTRACT: The present work is based on the analysis and presentation of arguments against and in favor of the school model of military and civic-military education in Brazilian public schools, demonstrating the legal interpretations existing in the divergences for the development and implementation of this teaching model, evidencing the articles of the Law of National Education Guidelines and Bases with the provisions in the Federal Constitution of the Federative Republic of Brazil, as well as its principles. Aiming to demystify the content, it demonstrates the bases of hierarchy and discipline, as well as the difficulties faced in the school environment, the foundations for the existence or not of the militarized school model, and ending, the conclusion that we are far from reaching a model ideal of education, there should be a plurality of models to be offered according to social concerns. To this end, an exploratory methodology was used to shed light on the conflicting points of academic and political debates on the subject.

Keywords: Hierarchy and discipline. Education. Military School.

\footnotetext{
${ }^{\mathrm{I}}$ Mestrando em Educação pela Faculdade de Teologia e Ciências - FATEC. Especialista em Direito Militar pela Faculdade Dom Alberto - Santa Cruz do Sul, RS. Especialista em Docência no Ensino Superior - Instituto Tratos - Brasília, DF. Graduado em Direito pela FINOM - Paracatu, MG. Fez parte dos Quadros de Praça da Polícia Militar de Minas Gerais (PMMG), realizando o curso técnico em Segurança Pública (CTSP-2007). Atua na Polícia Militar do Distrito Federal -PMDF desde o ano de 2014, possuindo o Curso de Operações de Choque - IX COC (2015), Curso Tático Operacional XIICTOP (2016), Curso de Operações Químicas -X COQ(2017). Email: guirra_guirra@yahoo.com.br
} 


\section{INTRODUÇÃO}

O presente trabalho visa demonstrar os pontos vista sobre a Escola cívico-militar. Deste modo apresenta as bases do ensino, sua origem e os argumentos favoráveis e contrários para a sua existência enquanto modelo de escola. A Educação constitui uma das práticas socioculturais que mais influenciam na existência dos seres humanos, considerando a sua profundidade, amplitude e abrangência.

A função social da escola pública é algo complexo que nos leva a vários questionamentos e contextos. Ao pensarmos o cotidiano escolar e a nossa prática, observamos que o processo ensino aprendizagem, elemento central da ação da escola, está diretamente influenciado pela relação social dos indivíduos que o realizam.

A Educação é reconhecidamente um dos pilares para o desenvolvimento do país, através do ensino é possível formar cidadão capacitados para desenvolvimento de suas habilidades em prol de uma sociedade na busca do progresso e melhorias para a convivência e continuidade social. Os Educandos devem estar capacitados para serem trabalhadores, desenvolvendo pesquisas e promovendo a construção de cidadãos capazes de entender a realidade de maneira crítica, fundamentando suas decisões não só na emoção, mas também permitindo que o racional tenha espaço nas tomadas de decisões.

Dentre os vários questionamentos de educadores e estudiosos sobre esse tema tão fascinante que é a Educação, surge a necessidade do debate para o modelo ideal de educação. Depois de traçado os planos e metas, tem-se a necessidade de esclarecer e positivar os objetivos as serem alcançados e o modelo/metodologia de ensino que será aplicado para que essas metas e objetivos específicos sejam alcançados.

No Brasil, existem essencialmente quatro modelos de escolas: as públicas, as militares, as cívico-militares e as particulares. Elas diferem entre si principalmente em relação ao financiamento, forma de ingresso, gestão e na proposta didático-pedagógica. A hierarquia e disciplina são pilares da Forças Armadas do Brasil, trazendo-as para a esfera educacional em busca de resultados condizentes com as expectativas atuais do ensino, que é lançar os estudantes no mercado de trabalho. 


\section{HIERARQUIA E DISCIPLINA}

Hierarquia significa o conjunto de poderes subordinados uns aos outros, classificando os patamares do poder correspondente às diferentes classes. Hierarquia é a ordenada divisão dos poderes com subordinação sucessiva de uns aos outros, é uma série contínua de graus ou escalões, em ordem crescente ou decrescente, podendo-se estabelecer tanto uma hierarquia social, uma hierarquia urbana, militar, ou qualquer outra área de convívio entre as partes.

A disciplina é o exato cumprimento dos deveres, traduzindo-se na rigorosa observância e no acatamento integral das leis, dos regulamentos, das normas e ordens por parte de todos os integrantes de uma instituição. O Manual de Campanha de Ordem Unida, do Exército Brasileiro, define Disciplina:

Disciplina é a força principal dos Exércitos. A disciplina, no sentido militar, é o predomínio da ordem e da obediência, resultante de uma educação apropriada. Disciplina militar é, pois, a obediência pronta, inteligente, espontânea e entusiástica às ordens do superior. Sua base é a subordinação voluntária do indivíduo à missão do conjunto, do qual faz parte. A disciplina é o espírito da unidade militar.

A hierarquia e a disciplina são decorrências da racionalidade humana, dando foco no

antropocentrismo humanista, em substituição ao teocentrismo medieval. Com efeito, intensas transformações sacudiram os dogmas religiosos e abalaram os seus domínios, colocando em cena atores sociais que, de figurantes, tornaram-se protagonistas, orquestrando a economia, apoiada pelas inovações científicas.

Transformações nas relações de poder, sociedade, política, economia e no próprio modo de ser dos indivíduos, afetou o saber e as práticas sociais, que se atualizaram em diversas instituições. Impregnadas por essa racionalidade, determinadas organizações, tais como as militares, se imbuíram de ordenar as relações sociais e de construir sujeitos segundo uma ordem racional moralizante, em consonância com o modelo econômico/político atual.

Os indivíduos e seus relacionamentos ganharam inteligibilidade por meio da concepção do mundo visto como máquina, tornando-se objeto das ciências comprometidas com a lógica da produtividade (LUZ, 1988).

\section{ALGUMAS DAS DIFICULDADES ENCONTRADAS NAS ESCOLAS.}

Diuturnamente somos bombardeados de informações nos dando conta da violência no interior das escolas. Alunos que agridem os professores, adolescentes que matam outros 
adolescentes no interior das escolas, bullying escolar, dentre outras situações que prejudicam o bom andamento do ensino dentro das escolas.

A falta de um ambiente seguro voltado para uma cultura de paz é um dos grandes problemas a serem enfrentados. Professores amedrontados pela violência da comunidade em que a escola está inserida e pelas posturas agressivas de alunos e famílias, se sentem impotentes para transformar algumas realidades.

Ser professor nunca foi uma tarefa simples, porém a prática de docente tem sido mais complexa, o professor tem perdido o seu prestígio e consequentemente sua autoridade em sala de aula, tais ações tem se tornado problemáticas, pois o ambiente escolar já não está sendo uma local para a aprendizagem com foco no desenvolvimento social, mas qualquer outra coisa, com um mescla de entretenimento desconstrutivista.

Os alunos estão desenvolvendo comportamentos agressivos face aos professores, que em grande parte não possuem amparo para tomada de decisões mais rigorosas, como outrora, por exemplo, o docente possuía autonomia para retirar o discente da sala de aula. Para Contreras (2002), a autonomia está sendo como as propagandas que se desgastam com o passar do tempo devido ao excesso de trabalho que é exposto, ao se falar de autonomia acaba se envolvendo também a relação professor/aluno e sociedade. Os professores sofrem com a má qualidade de ensino perdendo junto com ela o prazer pela profissão deixando junto a sua autonomia.

O desinteresse familiar no acompanhamento do filho em fase educacional tem-se demonstrado um fator negativo na melhoria de conquistas positivas para o ensino. Para que haja uma educação completa e bem-sucedida, é preciso que os pais façam parte dela participando da gestão democrática da escola, acompanhando de perto os processos de aprendizagem dos filhos, seja para incentivá-los, seja para apoiá-los a vencer as dificuldades encontradas.

\section{A MILITARIZAÇÃO DAS ESCOLAS: OPINIÕES DIVERGENTES}

O início da militarização nas escolas, remonta a Prússia, no século XVIII, onde por ordem de Frederico I em " 1717 , ordenou a frequência obrigatória de todas as crianças nas escolas estatais e, em atos posteriores, seguiu com a disposição para a construção de mais escolas”. (ROTHBARD, 2013, p34).

Com efeito, o século XVIII marcou o início da educação pública estatal prussiana, cujo objetivo era propiciar o engrandecimento do Estado. Luzuriaga (1959, p.I5I) esclarece que, do 
ponto de vista das autoridades prussianas, a educação respondia à "(...) necessidade de contar com súditos dóceis, bons soldados e funcionários idôneos". A rede de escolas públicas da Prússia, que gradativamente se estendeu pelas demais unidades políticas alemãs, foi também muito admirada, conforme se depreende do relato elaborado em 1866 pelo inspetor de ensino da França, J. M. Baudoin:

[...] em nenhuma parte, a instrução está tão difundida, nem é dada com tanto interesse, nem dirigida com tanto cuidado. $O$ menor povoado tem sua escola primária; a mais insignificante cidade, seu ginásio, suas escolas médias, perfeitamente organizadas, dotadas e cuidadas. $\mathrm{Na}$ Alemanha todos se interessam pela juventude: os mais altos personagens e as mais ilustres senhoras lhes dedicam seu tempo, seu dinheiro, sua experiência, os melhores escritores redigem livros para as crianças; os poetas compõem, para as lições de ginástica e de canto, poesias que os mais ilustres compositores não têm desdenhado colocar música. Todo o povo alemão está convencido de que se ocupar da instrução da juventude é cumprir um dever pessoal e trabalhar para o futuro do país. Cada um, se faz voluntariamente Volkserzieher, mestre do povo, e contribui por sua vez para o progresso da instrução geral. (Apud Capel, 1988, p. 89)

A pedagogia prussiana liberal no Brasil se dissemina por meio da ideia de disciplina e rigor. A educação prussiana tem sua prática embasada em fundamentos conceituais de uma filosofia disciplinar. O modelo prussiano defende a gratuidade e universalidade do ensino pautado na laicidade, e é influenciado pelas ideias iluministas. A educação prussiana é liberal porque tem como objetivo fundamentar o adestramento das consciências, imprimir a produtividade do capital e a competitividade.

Existe um consenso em relação ao fato de que a educação representa elemento de fundamental importância para viabilizar o crescimento econômico, existindo forte correlação entre a educação e a taxa de crescimento do PIB per capita entre os países. A educação aumenta a produtividade e a criatividade das pessoas, e promove o empreendedorismo e os avanços tecnológicos.

Os Colégios Militares do Exército ocupam um importante papel na educação do país. O primeiro deles foi fundado, ainda no período imperial, no ano de 1889 , após o Decreto Imperial $\mathrm{n}^{\circ}$ I0.202 assinado por D. Pedro II, com sede no Rio de Janeiro, com o nome de Imperial Colégio Militar da Corte, era dedicado aos filhos, de sexo masculino, dos militares brasileiros.

O Sistema de Ensino do Exército mantém, de forma adicional às modalidades militares propriamente ditas, o ensino preparatório e assistencial de nível fundamental e 
médio, por intermédio dos Colégios Militares, na forma da legislação federal pertinente, ressalvadas suas peculiaridades.

Desde então, essa modalidade de ensino se expandiu, garantindo também o acesso a discentes do sexo feminino roo anos após sua criação e aos filhos de civis. Tinha como principal objetivo a educação assistencial, e sua criação se deu mediante esforços do ministro da guerra Conselheiro Thomaz José Coelho de Almeida, inspirado em planos do Duque de Caxias (SOARES, 2002). Os Colégios Militares mantêm regime disciplinar de natureza educativa, compatível com a sua atividade preparatória para a carreira militar.

Outra vertente, são os colégios cívicos-militares, que obteve avanço com o Decreto Presidencial $n^{\circ}$ Io.004/2019, que institui o Programa Nacional de Escolas Cívico-Militares PECIM. A militarização da escola pública no Brasil se dissemina por meio da ideia de disciplina e rigor. A participação de militares nas escolas de gestão cívico-militar limita-se à segurança intra e extraescolar e à disciplina discente, estendendo-se a outras áreas apenas em caráter excepcional.

Atualmente são 93 escolas que atendem mais de 30 mil estudantes, e um dos estados com maior número de escolas militares é Goiás. A gestão cívico-militar tem por finalidade o controle de situação extrema de evasão e violência intra e extraescolar, promovendo a melhoria na qualidade da educação básica no ensino fundamental e no ensino médio.

As decisões disciplinares nas escolas de gestão cívico-militares devem ser tomadas conjuntamente entre os militares e as equipes pedagógicas, respeitado o projeto político pedagógico da escola. O modelo de Escola Cívico-Militar é o conjunto de ações promovidas com vistas à gestão de excelência nas áreas educacional, didático-pedagógica e administrativa, baseada nos padrões de ensino adotados pelos colégios militares do Comando do Exército, das polícias militares e dos corpos de bombeiros militares.

O modelo militar de educação é pautado no regime disciplinar, onde a base do agir são as regras presentes na rígida hierarquia, as reprimendas às ações indesejadas e a premiação dos bons comportamentos. Nessas escolas que além da disciplina como carro chefe, existe um processo seletivo concorrido. Com exceção dos filhos de militares, que na maioria dos casos, possuem vaga garantida, os filhos da população civil passam por testes seletivos. A média de concorrência é sempre elevada, chegando em certos locais a possuírem mais de 80 candidatos por vaga.

Uma crítica ao modelo de ensino militar, está no fato de ser um modelo disciplinar que segue a tradição prussiana, com fins utilitaristas disciplinares e de cunho mercadológico, criada para fins servis estatais. O foco da educação militarizada é o tecnicismo e o 
cientificismo, dando seguimento à estrutura de educação que padroniza valores a serviço da competitividade.

Outra situação exposta por críticos, é o fato desse modelo de ensino não preparar o aluno para que ele seja autônomo na construção do próprio conhecimento. A capacidade do aluno em aplicar os conhecimentos em seu dia a dia é uma das diretrizes da Base Nacional Comum Curricular (BNCC), que também prevê o desenvolvimento de habilidades socioemocionais no ambiente escolar, sendo que tal modelo estaria contrariando tais preceitos.

A hierarquia e disciplina são confrontadas por alguns professores e estudiosos do tema, sob o argumento de que as nossas escolas necessitam de mais disciplina, sim, mas uma disciplina para o estudo e não para a obediência. $O$ culto à autoridade e a utilização de regras para reduzir as individualidades de cada aluno criam, uma espécie de formatação social padrão, que contém ainda o incentivo de aceitação de uma ordem estabelecida.

Direcionando o olhar para outras escolas públicas, existem opiniões de que a militarização nas escolas do Estado, tem criado cisão dentro da escola pública, deixando a escola não militarizada abandonada pela Secretaria de Educação. Questionam até mesmo, a Constitucionalidade das Escolas Militarizadas, ou seja, se o modelo proposto está de acordo com os preceitos constitucionais, afirmando que existe um desvio de função da polícia e dos órgãos militares em prover esse serviço público, inclusive considerando que não têm dado conta de cumprir com sua função primária, na segurança pública.

Demonstram que Constituição Federal vigente e a legislação educacional brasileira são precisas ao determinarem que a educação básica é de responsabilidade prioritária das pastas de educação estaduais e municipais, e não de outros órgãos.

$\mathrm{Na}$ perspectiva do direito à educação, demonstram violação dos princípios da "liberdade de aprender, ensinar, pesquisar e divulgar o pensamento, a arte e o saber", do "pluralismo de ideias e de concepções pedagógicas" e da gestão democrática do ensino público, na forma da lei (incisos II, III e VI do art. 206 da Constituição Federal).

A Lei de Diretrizes e Bases da Educação, por sua vez, ao regulamentar a prerrogativa de autonomia das escolas determina que esta deve ser progressivamente assegurada, em vertente oposta à intervenção de militares na gestão escolar (LDB, art. 15).

Os professores reivindicam que esse modelo desvaloriza a carreira do magistério, pois a LDB em seu artigo 6I, positiva quem deve estar lecionando em sala de aula, são professores e trabalhadores da educação com habilitação específica e não militares das forças armadas e policiais militares, que constitucionalmente possuem atribuições de Defesa da Pátria e manutenção e preservação da Ordem Pública. 
Sob a espectro militar, os apoiadores do sistema de ensino cívico-militar, descrevem um ensino pautado na disciplina, na hierarquia e na autoridade, constituindo os pilares de toda a estrutura organizacional. A submissão às regras estabelecidas pelo ordenamento jurídico é outra máxima proferida nas escolas cívico-militares.

Tendo em vista os problemas existentes nas escolas por todo o Brasil, dentre eles: ações contra o patrimônio - depredações, pichações - formas de agressão interpessoais, sobretudo entre os próprios alunos, o sistema cívico-militar demonstra resultados positivos na coibição desses atos.

Um dos fatores que contribuem para os resultados positivos referente a ordem e bons resultados no Índice de Desenvolvimento da Educação Básica (Ideb), está justamente na massiva prática e teórica exposição de valores comportamentais, proporcionando a construção de limites que está diretamente ligada na capacidade do estudante em desenvolver a socialização e convivência bem-sucedidas, de forma que reconheça e considere os próprios limites e os dos demais.

A exigência do uniforme nas escolas cívico-militares, tem como finalidade a padronização. $O$ traje desempenhava uma função niveladora importante, por meio do uniforme escolar tem-se por referência um artefato cultural que reproduz os padrões estéticos e morais, criando uma ideia de coletividade e democratização do ensino.

Os artefatos visam auxiliar a introdução de regras e disciplinas na vida dos alunos: os livros, as carteiras escolares, o próprio uniforme, entre outros, funcionam como elementos complementares destinados à ação ordenadora e regulamentadora das normas da instituição sobre os estudantes. Implementando a educação moral e cívica, que busca em suas raízes as doutrinas do liberalismo, do conservadorismo, do positivismo e da segurança nacional.

A utilização do uniforme tem como fundamento a obtenção de uma igualdade que deve ser expressa por meio de uma mesma estética, imposta a todos, no intento de diminuir ou nivelar as diferenças sociais. Embora existam críticas sobre a uniformização, conforme afirma Lurie (1997, p. 33), após apelidar os uniformes de "roupa clichê", que "a forma extrema de roupa convencional é o traje totalmente determinado pelo outro: o uniforme. Independentemente do tipo (...) vestir uma dessas fardas é abdicar o direito de agir individualmente".

Em defesa da presença de militares e policiais militares nas escolas, existem as interpretações pela constitucionalidade do método de ensino e formação pedagógica. $O$ ordenamento jurídico brasileiro compreende uma série de textos legais e normas que 
estabelecem a ordem e regulamenta relações de serviço, prestações, obrigações, direitos e deveres de todos aqueles em território nacional.

Mesmo que exista reserva de vagas destinadas a filhos de militares, no caso das escolas militares, alguns entendem que o fato da educação não ser atividade fim da Polícia Militar, portanto, esse exercício deve refletir algum benefício para a corporação de algum modo, o que justificaria a reserva especial de vagas exclusivas para descendentes de servidores da Polícia Militar.

\section{CONCLUSÃO.}

Por fim, tendo exposto os pontos relevantes favoráveis e contrários ao modelo de escolas militares e cívico-militares, observa-se que existe embasamentos técnicos para ambos os lados. Entretanto cabe evidenciar que estamos longe de encontrar um modelo ideal, tendo em vista as dimensões territoriais do país e a especificidade de cada região e população pertencente aquela localidade.

Devemos ter em mente que a busca por resultados melhores e condizentes com as expectativas dos pais e educadores, naturalmente abre espaços para métodos e modelos de escolas diferentes. A depender de qual finalidade os pais e estudantes buscam, existirá um modelo para aquela finalidade.

A educação é multidisciplinar, existindo um conjunto de disciplinas que são estudadas de maneira simultânea, mas sem a necessidade de estarem relacionadas entre si, por esse viés, a educação se faz presente tanto na formalidade - sala de aula, professores e alunos - quanto na educação informal - não havendo horários, lugares ou currículos - a qual os conhecimentos são partilhados em meio a uma interação sociocultural que tem, como única condição necessária e suficiente, existir quem saiba e quem queira ou precise saber.

Sob a perspectiva do ensino cívico-militar, pautada na hierarquia e disciplina, padronização de comportamentos, respeito aos valores familiares e símbolos nacionais, com foco em permitir aos alunos, capacidade cognitiva de competição para o mercado de trabalho, aos interessados nesse tipo de modelo de ensino, existe opção de frequentarem tal modelo pedagógico/escolar.

O Decreto-Lei n. 869, de 12 de setembro de 1969 (BRASIL, 1969), instituiu como obrigatória a disciplina Ensino Moral e Cívico - EMC, nas escolas de todos os graus (níveis, na nomenclatura atual) e modalidades dos sistemas de ensino no país, tendo sido previsto nos currículos das escolas públicas até meados da década de 1980. Em 1993, após a promulgação da 
Lei n. 8.663 (BRASIL, 1993), que revogou o referido decreto, a EMC foi oficialmente retirada do currículo das escolas brasileiras, fator que não significou o abandono de suas premissas.

No momento político da atualidade, tendo em vista o Presidente da República Jair Bolsonaro ter sido militar do exército e apresentar em sua agenda de governo, dentre outros aspectos, a criação da Subsecretaria de Fomento às Escolas Cívico-Militares, por meio do Decreto n. 9.665, de 2 de janeiro de 2019 (BRASIL, 2019). As escolas cívico-militares, se constituíram como pauta do programa de governo, a partir de uma proposta de gestão compartilhada entre as Secretarias de Educação e de Segurança Pública para reorganização da instituição escolar.

É muito difícil, mesmo entre especialistas, chegar-se a uma noção do que seja qualidade de ensino. A escolha da melhor metodologia depende da forma como o estudante se relaciona com a prática, a filosofia educacional, as propostas de estudo e o ambiente da escola. Vai depender também qual expectativas dos pais com aprendizagem dos filhos, o que se busca com a educação, para o futuro da criança/adolescente que serão adultos já inseridos na sociedade.

Assim, o modelo cívico-militar, não é o solucionador para todas as dificuldades enfrentadas pelas escolas espalhadas por todo o Brasil, mas uma das diversas opções de escolhas dos pais que estejam ideologicamente alinhados com o modelo de ensino/escola ofertados tanto pelo Estado, quanto por empresas de ensino particular.

A vivência em um país Republicano e Democrático permite essa diversidade de modelos escolares, onde pessoas em todas as circunstâncias tomam decisões, quanto ao que se pretende atingir ou alcançar. Pois é intervindo sobre o meio, através de sua ação intencional e inteligente, que o homem humaniza o meio e a si mesmo, promovendo a mudança social que acredita.

\section{REFERÊNCIAS}

BRASIL. Constituição (1988). Constituição da República Federativa do Brasil. Brasília, DF: Centro Gráfico, 1988.

BRASIL. Ministério da Educação. Lei no 9.394, de 20 de dezembro de 1996. Estabelece as diretrizes e bases da educação nacional.

BRASIL, Ministério da Defesa, Exército Brasileiro, Comando de Operações Terrestres, Manual de Campanha Ordem Unida, EB7o-MC-ro.308, 4 à Edição, 2019. 
CAPEL, H. Filosofia y ciência en la geografia contemporânea: una introducción a la geografia. 3. ed. Barcelona: Barcanova, 1988.

CONTRERAS, J. A Autonomia Dos Professores. São Paulo: Editora, Cortez, 2002.

LURIE, Alison. A linguagem das roupas. Rio de Janeiro: Racco, 1997.

LUZ, Madel Therezinha. Natural, racional, social: razão médica e racionalidade científica moderna. Rio de Janeiro: Campus, 1988.

LUZURIAGA, L. História da educação e da pedagogia. São Paulo: Nacional, 1959.

ROTHBARD, Murray N. Educação: livre e obrigatória. Trad. Filipe Rangel. CeleMises Brasil: São Paulo, 2013.

SOARES, A. M. I. (2002). O colégio militar de Curitiba: a mentalidade desejada. In: Seminário de Pesquisa em Educação Região Sul, 4., Mesa Redonda no 35, UFPR, 2002. 